\title{
Role of carbonate on arsenic mobilization in groundwater
}

\author{
X.B. Gao, P.L. Gong \& W.T. Luo \\ School of Environmental Studies, China University of Geosciences, Wuhan, China
}

\begin{abstract}
As a highly toxic element, arsenic (As) contamination of groundwater causes challenging environmental and health concerns worldwide. Carbonate system has a significant effect on the migration and transformation of trace elements in groundwater. In this study, we do batch adsorption (isothermal, kinetic adsorption) experiments of arsenic with the synthesized calcite. And some characterization methods were employed. The results show that: (1) the adsorption capability was affected by the initial con-centration of arsenic, (2) The adsorption of $\mathrm{As}(\mathrm{V})$ on calcite was a comparatively fast reaction within the first $10 \mathrm{~h}$, and when the reaction time reached $72 \mathrm{~h}$, it seemed to have reached a balanced state of sorption and desorption. The research results could help in enriching the scientific understanding of the environmental behavior of synthesized calcite, with great theoretical and practical significance for the further study of the interaction with arsenic in carbonate system and environment.
\end{abstract}

\section{INTRODUCTION}

As a highly toxic element, arsenic (As) contamination of groundwater causes challenging environmental and health concerns worldwide (Nordstrom, 2002; Smedley \& Kinniburgh, 2002). In recent years, especially in Asia, with the development of industry and agriculture, the arsenic pollution in the groundwater is very serious, which directly threatens the health of the local residents.

As the second major minerals on the earth's surface, carbonates are widely distributed in groundwater system (Monteshernandez et al., 2009). They directly affect the migration and transformation of elements in groundwater, which including arsenic (Yokoyama et al., 2012; Wei et al., 2003).

\section{METHODS/EXPERIMENTAL}

Calcite were prepared with addition of a mixed solution of $\mathrm{CaCl}_{2}\left(0.5 \mathrm{M} \mathrm{L}^{-1}\right)$, polyacrylic acid and dextran sulfate sodium (to restrain the formation of aragonite), while $\mathrm{Na}_{2} \mathrm{CO}_{3}\left(0.5 \mathrm{M} \mathrm{L}^{-1}\right)$ solution was added to carry out precipitation reaction.

The batch adsorption (isothermal, kinetic adsorption) experiments were carried out to investigate the interfacial interaction of $\mathrm{As}(\mathrm{V})$ on calcite. The concentrations of corresponding arsenic were: $0,20,50$, $100,150,200,300 \mu \mathrm{M} \mathrm{L}^{-1}$. We set up three parallel samples) in the isothermal adsorption, the reaction time was $10,20,30 \mathrm{~min}$ and $1,3.5,6,10.5,24,48,72 \mathrm{~h}$ with the same concentration of arsenic $\left(30 \mu \mathrm{M} \mathrm{L}^{-1}\right)$ in the kinetic adsorption.

Characterization methods, such as Laser Particle Size Analyzer, XRD, FTIR and SEM, were employed to determine the difference of prepared calcite and calcite after their interaction with $\mathrm{As}(\mathrm{V})$ in surface morphology, polymorphs and chemical elements $(\mathrm{Xu}$ et al., 2013; Leeuw \& Parker, 1998).

\section{RESULTS AND DISCUSSION}

\subsection{Isothermal adsorption}

The isothermal experiment investigated the capacity of calcite on arsenic with different As initial concentrations.

The adsorption capability is affected by the initial concentration of arsenic. When the arsenic content had increased, the amount of arsenic adsorbed on calcite exhibited an increased trend (Fig. 1). The amount of sorbed arsenic increased linearly with solution As concentration.

\subsection{Kinetic adsorption}

The kinetic evaluation (Fig. 2) in this study had shown that the adsorption of $\mathrm{As}(\mathrm{V})$ by calcite was a comparatively fast reaction within the first $10 \mathrm{~h}$, followed by a slower and at a relatively constant reaction rate until equilibrium was achieved. After that, the adsorption rate might have decreased. When the reaction time reached $72 \mathrm{~h}$, it seemed to have reached a balanced state of sorption and desorption.

\subsection{Characterization}

The synthesized calcite, had an average particle diameter of approximately $30 \mu \mathrm{m}$, ranging from 25 to $45 \mu \mathrm{m}$.

Synthesized calcite (Fig. 3a) had good monodispersity without adhesion phenomenon. After adsorption, 


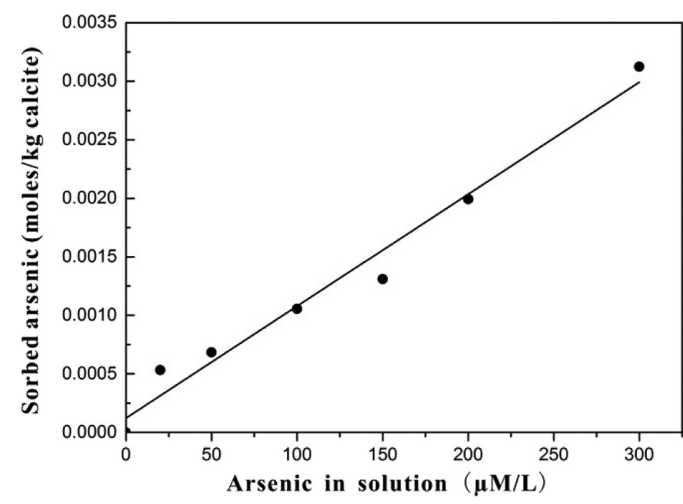

Figure 1. Adsorption isotherms of arsenic on calcite at different initial concentration of arsenic.

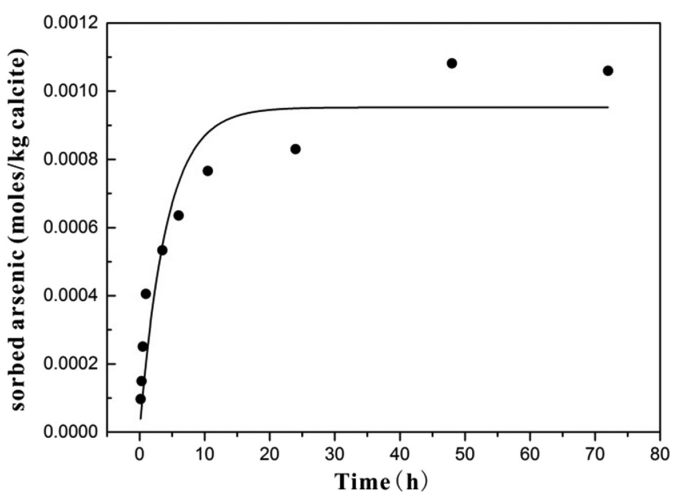

Figure 2. The results of the kinetic uptake experiments as a function of time.

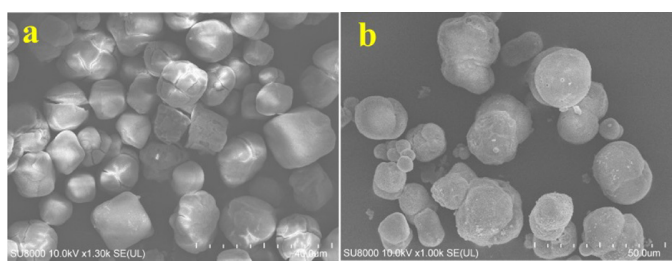

Figure 3. SEM images of (a) Synthesized calcite; (b) calcite after adsorption.

the SEM image (Fig. 3b) showed the increased aggregation and surface pore volume of calcite particles due to the impact of arsenic adsorption. Comparing with Figure $3 \mathrm{a}$ and $3 \mathrm{~b}$, morphology of calcite got slightly rounded after reaction with arsenic.

\section{CONCLUSIONS}

The results of this research showed that: (i) The adsorption capability is affected by the initial concentration of arsenic, and the amount of sorbed arsenic increased linearly with solution concentration; (ii) The adsorption of $\mathrm{As}(\mathrm{V})$ by calcite was a comparatively fast reaction within the first $10 \mathrm{~h}$, and when the reaction time reached $72 \mathrm{~h}$, it seemed to have reached a balanced state of sorption and desorption.

\section{REFERENCES}

de Leeuw, N.H. \& Parker, S.C. 1998. Surface structure and morphology of calcium carbonate polymorphs calcite, aragonite, and vaterite: An atomistic approach. J. Phys. Chem. B 102(16): 2914-2922.

Montes-Hernandez, G., Concha-Lozano, N., Renard, F. \& Quirico, E. 2009. Removal of oxyanions from synthetic wastewater via carbonation process of calcium hydroxide: applied and fundamental aspects. J. Hazard. Mater. 166(2-3): 788-795.

Nordstrom, D.K. 2002. Worldwide occurrences of arsenic in ground water. Science 296(5576): 2143-2145.

Smedley, P.L. \& Kinniburgh, D.G. 2002. A review of the source, behaviour and distribution of arsenic in natural waters. App. Geochem. 17(5): 517-568.

Wei, H., Shen, Q., Zhao, Y., Wang, D.J. \& Xu, D.F. 2003. Influence of polyvinylpyrrolidone on the precipitation of calcium carbonate and on the transformation of vaterite to calcite. J. Cryst. Growth 250(3-4): 516-524.

Xu, J., Yan, C., Zhang, F., Konishi, H., Xu. H. \& Teng H.H. 2013. Testing the cation-hydration effect on the crystallization of Ca-Mg-CO $\mathrm{CO}_{3}$ systems. P. Natl. Acad. Sci. USA. 110(44): 17750-17755.

Yokoyama, Y., Tanaka, K. \& Takahashi, Y. 2012. Differences in the immobilization of arsenite and arsenate by calcite. Geochem. Cosmochim. Acta 91(91):202-219. 